\title{
"EMPENG" EFEKTIF MENURUNKAN NYERI BAYI SAAT PENGAMBILAN DARAH VENA
}

\author{
Dyah Dwi Astuti ${ }^{1}$, Yeni Rustina ${ }^{2}$, Fajar Tri Waluyanti ${ }^{2}$
}

1. Akademi Keperawatan Pemerintah Provinsi Jawa Tengah, Jalan Pakuwojo Kejiwan, Wonosobo 56311, Indonesia

2. Fakultas Ilmu Keperawatan, Universitas Indonesia, Jalan Prof. Dr. Bahder Djohan, Depok 16424, Indonesia

*E-mail: fajar_tri@ui.ac.id

\begin{abstract}
Abstrak
Prosedur pengambilan darah vena dapat menimbulkan nyeri pada bayi berat lahir rendah. Penelitian ini bertujuan mengidentifikasi perbedaan tingkat nyeri selama pengambilan darah vena setelah dilakukan perawatan metode kanguru dan pemberian empeng. Desain penelitian adalah eksperimen acak terkontrol pada 21 bayi berat lahir rendah dengan teknik consecutive sampling. Penilaian respons nyeri menggunakan instrumen Premature Infant Pain Profile. Hasil analisis uji $\mathrm{t}$ independen menunjukkan bahwa terdapat perbedaan bermakna rerata respons nyeri pada kelompok perawatan metode Kanguru (rerata $=8,94)$ dan pemberian empeng (rerata= 5,08) $(\mathrm{p}=0,005)$. Pemberian empeng pada bayi berat lahir rendah dapat dijadikan sebagai intervensi keperawatan dalam asuhan atraumatik saat prosedur invasif minor.
\end{abstract}

Kata kunci: bayi berat lahir rendah, pemberian empeng, pengambilan darah vena, Perawatan Metode Kanguru, respons nyeri

\section{Abstract}

"Pacifier" Effective to Reduce Pain in Babies Undergoing Venous Blood Sampling. Venous blood sampling is a procedure which causes pain on low birth weight infants. This study aimed to identify the comparison of pain response between the infants that received Kangaroo Mother Care and the other group who used pacifier for during venous blood sample collection. The research design was randomized controlled trial on 21 low birth weight infants with consecutive sampling. Pain response was assessed by Premature Infant Pain Profile instrument. Independent t-test analysis showed that there were significant differences in mean pain response between Kangaroo Mother Care group $($ mean $=8,94)$ and pacifier group (mean= 5,08) $(p=0,005)$. Pacifier could be used as a nursing intervention in a traumatic care with minor painful procedure in low birth weight infants.

Keywords: Kangaroo Mother Care, low birth weight infants, pacifier, pain response, venous blood collection

\section{Pendahuluan}

Bayi berat lahir rendah (BBLR) berisiko mengalami masalah seperti, hipotermia, infeksi, sepsis, hipoglikemi, dan hipoksia. Kondisi di atas menyebabkan sebagian besar BBLR dirawat di ruang intensif untuk mendukung keberhasilan dalam periode transisi. BBLR terpapar berbagai stressor selama perawatan di ruang intensif seperti prosedur yang menimbulkan nyeri dan ketidaknyamanan, kebisingan, pencahayaan yang berlebih, perpisahan dengan ibu, dan gangguan tidur. Lingkungan perawatan tersebut akan berkontribusi terhadap kualitas kehidupan BBLR di masa depan (Lawn, Davidge, Paul, Xylander, Johnson, et al., 2013).

Hasil penelitian menunjukkan bahwa BBLR mengalami lebih dari sepuluh prosedur yang menyebabkan nyeri dan ketidaknyamanan selama perawatan di ruang intensif (AsadiNoghabi, Tavassoli-Farahi, Yousefi, \& Sadeghi, 2014). Penelitian Beheshtipoor, Memarizadeh, Hashemi, Porarian, dan Rambod (2014) melaporkan sebesar 55-86\% 
prosedur berhubungan dengan pengambilan darah vena. Beheshtipoor et al., (2014) menambahkan bahwa nyeri dan ketidaknyamanan yang ditimbulkan dari pengambilan darah vena yang berlangsung lama akan berdampak pada keterlambatan perkembangan bahasa, motorik, kognitif, dan memori, serta mengancam kehidupan BBLR.

Asuhan perkembangan merupakan salah satu pendekatan dengan menciptakan healing environment untuk mengurangi stimuli yang menimbulkan ketidaknyamanan pada BBLR. Intervensi keperawatan yang dapat dilakukan untuk mendukung healing environment selama pengambilan darah vena antara lain dengan penerapan Perawatan Metode Kanguru (PMK) dan pemberian empeng pada BBLR (Herliana, Wanda, \& Hastono, 2011). Penelitian ini bertujuan untuk mengidentifikasi perbedaan nyeri selama pengambilan darah vena pada BBLR pasca dilakukan PMK dan pemberian empeng.

\section{Metode}

Desain penelitian ini menggunakan eksperimen acak terkontrol dengan jenis rancangan rambang lugas (completely randomized design). Dua puluh satu BBLR yang dipilih secara consecutive sampling terlibat dalam penelitian, serta dikelompokkan menjadi kelompok PMK dan kelompok pemberian empeng. Kriteria inklusi penelitian ini adalah BBLR dengan berat lahir kurang dari 2.500 gram, berusia kurang dari 28 hari, usia gestasi dengan koreksi minimal 30 minggu berdasarkan penghitungan Ballard score test, suhu tubuh $36,5-37,5^{\circ} \mathrm{C}$, tidak memperoleh obat sedatif dan opioid 12 jam sebelum prosedur, dan orang tua atau penanggung jawab setuju menjadi responden penelitian. Penelitian ini telah lolos kaji etik dari Komite Etik Riset Fakultas Ilmu Keperawatan Universitas Indonesia. Alat pengumpul data yang digunakan adalah lembar observasi tentang karakteristik BBLR dan lembar observasi Prema- ture Infant Pain Profile (PIPP) untuk menilai respons nyeri.

Prosedur yang diberikan kepada kelompok intervensi PMK adalah melakukan PMK selama 15 menit sebelum prosedur pengambilan darah vena; sedangkan pada kelompok intervensi pemberian empeng, dilakukan minimal handling selama 15 menit dan dua menit sebelum prosedur BBLR diberikan intervensi pemberian empeng. Dua menit sebelum prosedur dilakukan penilaian (baseline) status perilaku, pengukuran saturasi oksigen dan denyut jantung. Penilaian PIPP dilakukan pada fase reaktivitas (menit pertama), fase regulasi (menit kedua), dan fase pemulihan (menit ketiga) selama pengambilan darah vena.

\section{Hasil}

Karakteristik BBLR dinilai dari variabel usia gestasi, usia kronologis, jenis kelamin, riwayat penyakit, dan riwayat pengambilan darah vena sebelumnya. Rata-rata usia gestasi pada kelompok intervensi PMK 34,10 minggu (SD 2,73 minggu; IK 95\% 32,15-36,06 minggu); sedangkan pada kelompok pemberian empeng mempunyai rata-rata sebesar 34,64 minggu (SD 3,23 minggu; IK 95\% 32,46-36,87 minggu). Karakteristik BBLR berdasar usia kronologis baik pada kelompok intervensi PMK dan pemberian empeng mempunyai median 4 hari.

Karakteristik BBLR berdasarkan jenis kelamin baik pada kelompok intervensi PMK dan pemberian empeng mempunyai persentase yang sama antara BBLR yang berjenis kelamin laki-laki dan perempuan yaitu sebesar $50 \%$ responden. Berdasarkan karakteristik riwayat penyakit seluruh BBLR pada kelompok intervensi PMK tidak mempunyai riwayat gangguan neurologis. Sementara pada kelompok intervensi pemberian empeng mayoritas responden tidak mempunyai riwayat gangguan neurologis $(90,9 \%)$. 
Berdasarkan karakteristik riwayat pengambilan darah vena sebelumnya pada kelompok intervensi PMK, BBLR yang tidak mempunyai riwayat pengambilan darah vena yaitu sebesar $70 \%$ responden. Pada kelompok intervensi pemberian empeng karakteristik BBLR yang tidak mempunyai riwayat pengambilan darah vena yaitu sebesar 54,54\% responden.

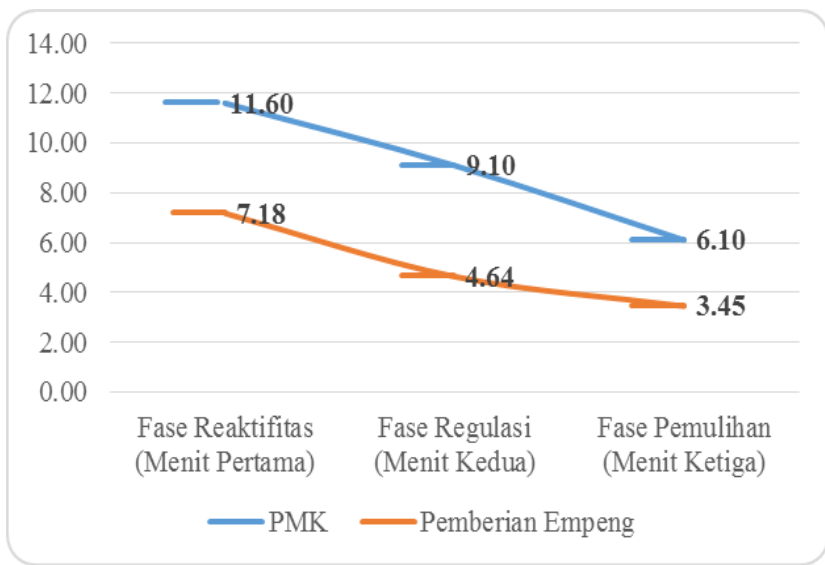

Gambar 1. Rata-rata Skor Nyeri Berdasarkan Penilaian PIPP pada Fase Reaktivitas, Fase Regulasi, dan Fase Pemulihan

Deskripsi skor nyeri berdasarkan penilaian PIPP dapat dilihat pada gambar 1. Hasil uji statistik menunjukkan bahwa rata-rata respons nyeri pada kelompok intervensi PMK sebesar 8,94 lebih tinggi dibandingkan dengan kelompok pemberian empeng sebesar 5,08. Perbedaan rata-rata antara kedua kelompok adalah 3,86 (IK 95\% 1,30-6,41). Terdapat perbedaan yang bermakna rata-rata respons nyeri pada kelompok intervensi PMK dan pemberian empeng $(p=0,005)($ Tabel 1$)$.

Tabel 1. Perbedaan Rata-Rata Respon Nyeri antara Kelompok Perawatan Metode Kanguru (PMK) dan Pemberian Empeng

\begin{tabular}{lccc}
\hline $\begin{array}{c}\text { Kelompok } \\
\text { Intervensi }\end{array}$ & $\begin{array}{c}\text { Rerata } \\
\text { Respons } \\
\text { Nyeri }\end{array}$ & $\begin{array}{c}\text { Perbedaan } \\
\text { Rerata } \\
(\text { IK 95\%) }\end{array}$ & p \\
\hline PMK & 8,94 & & \\
$\begin{array}{l}\text { Pemberian } \\
\text { Empeng }\end{array}$ & 5,08 & $3,86(1,30-6,41)$ & 0,005 \\
& & &
\end{tabular}

Selanjutnya hasil uji korelasi masing-masing karakteristik BBLR secara statistik menunjukkan hubungan yang lemah $(\mathrm{r}<0,4)$ dan tidak ada hubungan $(\mathrm{p}>0,05)$ dengan arah hubungan negatif pada variabel usia gestasi dan usia kronologis yang berarti semakin tinggi usia gestasi dan usia kronologis, maka semakin rendah respons nyeri pada BBLR (Tabel 2).

Tabel 2. Hasil Uji Korelasi Karakteristik Bayi Berat Lahir Rendah (BBLR) dengan Respon Nyeri Selama Pengambilan Darah Vena

\begin{tabular}{lcc}
\hline Karakteristik BBLR & $\begin{array}{c}\text { Nilai } \\
\text { Korelasi (r) }\end{array}$ & $\mathbf{p}$ \\
\hline Usia Gestasi & $-0,374$ & $0,095^{*}$ \\
Usia Kronologis & $-0,256$ & $0,263^{*}$ \\
Jenis Kelamin & 0,128 & $0,580^{*}$ \\
Riwayat Penyakit & 0,151 & $0,513^{*}$ \\
$\begin{array}{l}\text { Riwayat Pengambilan } \\
\text { Darah Vena } \\
\text { Sebelumnya }\end{array}$ & 0,220 & $0,338^{*}$ \\
\hline
\end{tabular}

Keterangan Uji Korelasi*: Usia gestasi dan usia kronologis dengan uji Pearson; sedangkan Jenis Kelamin, Riwayat Penyakit, serta Riwayat Pengambilan Darah Vena Sebelumnya dengan Uji Eta.

\section{Pembahasan}

Hasil uji statistik menunjukkan bahwa rerata respons nyeri pada kelompok intervensi PMK sebesar 8,94. Hasil penelitian ini sejalan dengan penelitian yang dilakukan oleh Mosayebi, Javadpour, Rahmati, Hagani, dan Movahedian (2014).

PMK sebagai intervensi non farmakologi selama pengambilan darah vena pada BBLR berhubungan dengan respons perilaku yang dikenal dengan istilah marsupial behavior of ventral maternal-infant contact (Johnston, Campbell-Yeo, Fernandes, Inglis, Streiner \& Zee, 2014). Respons perilaku tersebut berhu- 
bungan dengan kontak kulit ibu dan BBLR yang berdampak positif terhadap penurunan respons nyeri selama pengambilan darah vena dengan meningkatkan kondisi homeostasis. Kondisi homeostasis berefek pada pengeluaran hormon endorfin, oksitosin, dan serotonin yang berperan dalam inhibitor respons nyeri, serta meningkatkan kenyamanan pada BBLR dan ibu (Johnston, Campbell-Yeo, \& Fernandes, 2008).

Kontak kulit antara ibu dan BBLR juga bermanfaat untuk perkembangan ikatan emosional atau bonding antara ibu dan BBLR. Ikatan emosional tersebut menyebabkan ibu berespons sosial terhadap BBLR selama pengambilan darah vena seperti memberikan sentuhan terapeutik kepada BBLR. Respons sosial pada penelitian ini ditunjukkan dengan ibu membelai BBLR yang menangis dan menepuk-nepuk lembut BBLR pada saat dilakukan prosedur pengambilan darah vena (Johston et al., 2014).

PMK bermanfaat untuk stimulasi persyarafan sensorik indra penciuman dan pendengaran. Adanya kehadiran ibu menyebabkan BBLR dapat mendengar suara ibu. BBLR mengenali suara ibu karena adanya memori saat masa kehamilan. Hal tersebut meningkatkan kenyamanan pada BBLR. Penurunan respons nyeri juga disebabkan oleh adanya posisi pronasi seperti posisi di intrauterin (Johnston, CampbellYeo, \& Fernandes, 2008).

Intervensi PMK merupakan salah satu intervensi asuhan perkembangan dengan prinsip family centered care. Tujuan dari intervensi pada family centered care adalah mengurangi stress dan nyeri dengan melibatkan peran orang tua. Orang tua berperan sebagai pain killer bagi BBLR saat menghadapi kondisi yang menimbulkan stress dan ketidaknyamanan seperti saat pengambilan darah vena.

Penelitian ini menunjukkan rerata skor PIPP pada kelompok intervensi pemberian empeng sebesar 5,08. Liaw, Yang, Wang, Chen,
Chang, dan Yin (2012) menyimpulkan bahwa pemberian empeng mempunyai efek analgesik terhadap prosedur yang dapat menimbulkan nyeri.

Mekanisme pemberian empeng yang dapat menurunkan respons nyeri pada BBLR berhubungan dengan stimulasi orotaktil dan mekanoreseptor. Pemberian empeng menghambat impuls nosiseptif pada serat ascenden dan mengaktivasi serabut aferen yang dapat menyebabkan gerbang (gate) tertutup. Hal tersebut sesuai dengan mekanisme Gate Control Theory (Triani \& Lubis, 2006; Johnston, Fernandes, \& Campbell-Yeo, 2011).

Pemberian empeng pada BBLR selama pengambilan darah vena mengaktifkan hormon serotonin yang dikeluarkan oleh batang otak, yang selanjutnya menstimulus pengeluaran $\beta$ endorfin. Kedua hormon tersebut akan berpengaruh terhadap respons fisiologis dan perilaku pada saat pengambilan darah, sehingga terjadi penurunan denyut jantung, peningkatan saturasi oksigen, serta penurunan respons perilaku terhadap nyeri akibat pengambilan darah vena (Naughton, 2014).

Hasil penelitian ini menunjukkan terdapat perbedaan yang bermakna antara rerata respons nyeri pada kelompok intervensi PMK dan pemberian empeng. Pada penelitian ini intervensi PMK mempunyai rerata respons nyeri yang lebih tinggi dibanding kelompok intervensi pemberian empeng.

Hasil penelitian Castral, Warnock, Ribeiro, Vasconcelos, Leite, dan Scochi (2012) menyatakan bahwa stress ibu saat pelaksanaan PMK akan mempengaruhi respons nyeri khususnya peningkatan denyut jantung. Fernandes (2010) menunjukkan bahwa ibu dapat bereaksi negatif selama prosedur pengambilan darah vena seperti kecemasan dan ketakutan terhadap tindakan yang akan dilakukan kepada BBLR. Kemampuan orang tua untuk mengatur tingkat stress berkontribusi terhadap respons stress BBLR selama pengambilan darah vena. 
Faktor lain yang mungkin memengaruhi keefektifan PMK untuk menurunkan respons nyeri adalah lamanya PMK. Hasil telaah literatur yang dilakukan oleh Johnston et al. (2014) menyebutkan bahwa keefektifan PMK tergantung pada lamanya intervensi. Terdapat perbedaan bermakna antara intervensi PMK yang diberikan 15 menit, 30 menit, dan 80 menit dengan respons nyeri pada BBLR selama dilakukan prosedur yang menimbulkan nyeri.

Kesulitan yang dialami pada saat melakukan intervensi PMK pada penelitian ini adalah dalam memposisikan BBLR saat melakukan prosedur pengambilan darah vena. Pada intervensi ini dibutuhkan kehadiran orang tua, sehingga intervensi ini hanya dapat dilakukan pada prosedur pengambilan darah vena yang terjadwal. Pada intervensi ini membutuhkan waktu yang lebih untuk menyiapkan orang tua dan BBLR. Faktor lingkungan juga memengaruhi pelaksanaan intervensi PMK yaitu pencahayaan dan privasi (Johnston, CampbellYeo, \& Fernandes, 2008).

Intervensi pemberian empeng mempunyai rerata skor PIPP yang lebih rendah dalam penelitian ini. Hal ini menunjukkan bahwa intervensi pemberian empeng dinilai lebih efektif dibandingkan dengan intervensi PMK untuk menurunkan respons nyeri selama pengambilan darah vena pada BBLR.

Kelebihan intervensi pemberian empeng dibandingkan dengan intervensi PMK adalah intervensi ini lebih praktis yaitu tidak memerlukan waktu yang lebih lama untuk persiapan BBLR. Intervensi ini juga dapat dilakukan pada prosedur pengambilan darah vena yang tidak terjadwal karena tidak memerlukan kehadiran orang tua. Intervensi ini tidak memerlukan ruang khusus untuk menjaga privasi seperti pada intervensi PMK. Pemberian empeng memenuhi kebutuhan oral sesuai dengan teori psikoanalitik Freud. Teori tersebut menyatakan bahwa pada masa neonatus, BBLR berada pada tahap perkembangan oral, sehingga penghisapan akan memberikan rasa nyaman. Keterbatasan intervensi pemberian empeng adalah kurang menerapkan prinsip family centered care (Mirzarahimi, Mehrnoush, Shahizadeh, Samadi, \& Amani, 2013).

Telaah sistematik yang dilakukan Cignacco, Hamers, dan Stoffel (2007) menyatakan bahwa tipe empeng dan durasi pemberian empeng mempengaruhi respons fisiologis selama prosedur yang menimbulkan nyeri. Pelaksanaan intervensi pemberian empeng dipengaruhi oleh rasa lapar, ketidaknyamanan, temperamen BBLR, status bangun dan tidur, serta pengalaman nyeri (Mirzarahimi et al., 2013).

Hasil penelitian ini menunjukkan bahwa usia gestasi dan usia kronologis mempunyai hubungan yang lemah dan tidak bermakna terhadap respons nyeri selama pengambilan darah vena pada BBLR.

Riwayat paparan pengambilan darah vena sebelumnya mempunyai hubungan yang lemah dan tidak bermakna terhadap respons nyeri selama pengambilan darah vena. Hasil penelitian Goubet, Clifton, dan Shah (2001) menyatakan jumlah paparan prosedur invasif kurang dari lima kali tidak berpengaruh secara bermakna terhadap respons fisiologis dan ekspresi wajah pada BBLR. BBLR pada penelitian ini maksimal terpapar pengambilan darah vena sebanyak 3 kali, keadaan tersebut mungkin yang dapat menjelaskan sesuai hasil penelitian.

Variabel jenis kelamin pada penelitian ini mempunyai hubungan yang sangat lemah dan tidak bermakna terhadap respons nyeri selama pengambilan darah vena pada BBLR. Guinsburg, Araujo, Almeida, Balda, Berenguel, et al., (2000) menyatakan bahwa pengaruh jenis kelamin terhadap respons nyeri masih dalam perdebatan tergantung dari parameter respons nyeri yang digunakan.

Variabel riwayat penyakit neurologis pada penelitian ini mempunyai hubungan yang lemah dan tidak bermakna terhadap respons 
nyeri selama pengambilan darah vena pada BBLR. Adanya kerusakan atau infeksi terhadap bagian korteks otak akan berpengaruh terhadap persepsi nyeri (Badr et al., 2010; Cong, McGrath, Cusson, \& Zhang, 2013). Pada penelitian ini mayoritas BBLR tidak mempunyai riwayat penyakit neurologis, analisa peneliti keadaan tersebut yang dapat mendukung penemuan dalam penelitian ini.

\section{Kesimpulan}

Terdapat perbedaan yang bermakna antara rerata respons nyeri pada kelompok PMK dan pemberian empeng. Karakteristik variabel responden pada penelitian ini memiliki hubungan yang lemah dan tidak bermakna dengan respons nyeri selama pengambilan darah vena pada BBLR. Arah hubungan negatif pada variabel usia gestasi, usia kronologis, dan riwayat pengambilan darah vena sebelumnya.

Hasil penelitian ini dapat dijadikan bahan kajian dalam penyusunan standar operasional prosedur asuhan keperawatan yang bertujuan untuk menurunkan respons nyeri selama pengambilan darah vena pada BBLR. Pelayanan keperawatan dapat menerapkan intervensi pemberian empeng untuk asuhan atraumatik pada prosedur invasif minor sebagai salah satu penerapan asuhan perkembangan selama perawatan pada BBLR, sehingga dapat meminimalkan risiko gangguan perkembangan. Penelitian selanjutnya disarankan dapat menggunakan metode blinding dan masking, sehingga kualitas data dapat ditingkatkan (NN, HR, AM).

\section{Referensi}

Asadi-Noghabi, F., Tavassoli-Farahi, M., Yousefi, H., \& Sadeghi, T. (2014). Neonate pain management: What do nurses really know? Global Journal of Health Science, 6 (5), 284293. doi: $10.5539 / g j h s . v 6 n 5 p 284$

Badr, L.K., Abdallah, B., Hawari, M., Saadieh, S., Kassar, M., Nakad, P., \& Breidi, J. (2010). Determinants of premature infant pain responsses to heel sticks. Pediatric Nursing, 36 (3), 129-136. Diperoleh dari https://www.ncbi. nlm.nih.gov/pubmed/20687304

Beheshtipoor, N., Memarizadeh, A., Hashemi, F., Porarian, S., \& Rambod, M. (2014). The effect of kangaroo care on pain and physiological parameters in preterm infants on heel-stick procedure: A randomized controlled crossover study. Galen Medical Journal, 2 (4), 157-68. Diperoleh dari http://www.gmj.ir/index.php/g $\mathrm{mj} /$ article/download/80/pdf_13

Castral, T.C., Warnock, F.F., Ribeiro, L.M., Vasconcelos, M.G.L., Leite, A.M., \& Scochi, C.G.S. (2012). Maternal factors regulating preterm infants' responsses to pain and stress while in maternal kangaroo care. Latino-Am. Enfermagem, 20 (3), 435-43.

Cignacco, E., Hamers, J.P.H., Stoffeel, L., Lingen, R.A.V., Schutz, N., Muller, R., ..., Nelle, M. (2008). Routine procedure in NICU: Factors influencing pain assessment and ranking by pain intensity. Swiss Med WKLY, 138 (33-34), 484-491.

Cong, X., McGrath, J.M., Cusson, R.M., \& Zhang, D. (2013). Pain assessment and measurement in neonates. Advances in Neonatal Care, 13 (6), 379-395. doi: 10.1097/ANC.0b013e3182a 41452

Goubet, N., Clifton, R.K., \& Shah, B. (2001). Learning about pain in preterm newborns. Journal of Developmental \& Behavior Pediatrics, 22 (6), 421-424.

Guinsburg, R., Araujo, de P.A.C., Almeida, B.A.M.F., Balda, de C.X.R., Berenguel, C.R., Tonelotto, J., ..., Konelman, B.I. (2000). Differences in pain expression between male and female newborn infants. Pain, 85, 127133.

Herliana, L., Wanda, D., \& Hastono, S.P. (2011). Pengaruh developmental care terhadap respons nyeri akut pada bayi prematur yang dilakukan prosedur invasif di RSU Tasikmalaya dan RSU Ciamis. Jurnal Keperawatan Indonesia, 14 (3), 199-2011. 
Johnston, C., Campbell-Yeo, M., Fernandes, A., Inglis, D., Streiner, D., \& Zee, R. (2014). Skin to skin care procedural pain in neonates: Review. The Cochrane Library, 1, 1-82. doi: 10.1002/14651858.cd008435.pub2.

Johnston, C.C., Campbell-Yeo, M., \& Fernandes, A. (2008). Kangaroo mother care for procedural pain in preterm neonates. Neurology and Psychiatry, 80-82. Diperoleh dari http://repositorio.esenfc.pt/private/index. php? process $=$ download $\&$ id $=4866 \&$ code $=8052$ 70903

Johnston, C.C., Fernandes, A.M., \& CampbellYeo, M. (2011). Pain in neonates is disfferent. PAIN, 152 (8), S65-S73.

Lawn, J.E., Davidge, R., Paul, V.K., Xylander, S.V., Johnson, J.G., Costello, A., ..., Molyneux, L. (2013). Born too soon: Care for the preterm baby. Reproductive Health, 10 (Suppl 1), 1-19. doi: 10.1186/1742-4755-10S1-S5

Liaw, J.J., Yang, L., Wang, K.W.K., Chen, C.M., Chang, Y.C., \& Yin, T. (2012). Non-nutritive sucking and facilitated tucking relieve preterm infant pain during heel-stick procedures: A prospective, randomised controlled crossover trial. International Journal of Nursing Studies, 49 (8), 300-309. doi: http://dx.doi.org/10.1016 /j.ijnurstu.2011.09.017

Mirzarahimi, M., Mehrnoush, N., Shahizadeh, S., Samadi, N., \& Amani, F. (2013). Effect of non-nutritive sucking and leg massage on physiological and behavioral indicators of pain following heel blood sampling in term neonates. International Journal of Nursing Studies, 2 (2), 74-79. Diperoleh dari http://www.sciencepubco.com/index.php/IJAN S/article/view/578/762

Mosayebi, Z., Javidpour, M., Rahmati, M., Hagani, H., \& Movahedian, A.H. (2014). The effect of kangaroo mother care on pain from heel lance in preterm newborn admitted to neonatal intensive care unit: A crossover randomized clinical trial. J Compr Ped, 5 (4), 1-6. doi: 10.17795/compreped-22214

Nanavati, R., Balan, R., \& Kabra, N.S. (2013). Effect of kangaroo mother care vs expressed breast milk administration on pain associated with removal of adhesive tape in very low birth weight neonates: A randomized controlled trial. Indian Pediatrics, 50 (15), 1011-1015. Diperoleh dari http://indianpedi atrics.net/nov2013/nov-1011-1015.htm

Naughton, K.A. (2013). The combined use of sucrose and nonnutritive sucking for procedural pain in both term and preterm neonates. Advances in Neonatal Care, 13 (1), 9-19. doi: 10.1097/ANC.0b013e31827ed9d3.

Triani, E., \& Lubis, M. (2006). Penggunaan analgesia non farmakologis saat tindakan invasif minor pada neonatus. Sari Pediatri, 8 (2), 107-111. 